\title{
MALÁRIA: ASPECTOS HISTÓRICOS E QUIMIOTERAPIA
}

Tanos C. C. França*, Marta G. dos Santos e José D. Figueroa-Villar

Divisão de Ensino e Pesquisa, Seção de Engenharia Química, Instituto Militar de Engenharia, Praça General Tibúrcio, 80, 22290-270 Rio de Janeiro - RJ, Brasil

Recebido em 8/3/07; aceito em 6/9/07; publicado na web em 2/4/08

\begin{abstract}
MALARIA: HISTORICAL ASPECTS AND CHEMOTERAPY. Malaria is still a very serious worldwide public health problem affecting between 300 and 500 million people and causing from 1.0 to 2.5 million deaths annually. The major problems with this disease are the lack of efficient vaccines and the rapid emergence of chemotherapy resistant $P$. falciparum strains. In this work we present a synopsis and discussion on malaria to provide the readers with some information on the historical aspects and relevance of this disease as well as the chemotherapy in use today.
\end{abstract}

Keywords: malaria; historical of malaria; antimalaric chemotherapy.

\section{INTRODUÇÃO}

As chamadas doenças parasitárias afetam hoje em dia uma grande parcela da população mundial, provocando muitas mortes e exercendo uma grande influência limitante na qualidade de vida e no desenvolvimento de muitos países. Estas doenças podem ser provocadas por seres unicelulares mais simples, como protozoários, ou por seres multicelulares mais desenvolvidos, como os vermes.

Os protozoários são os responsáveis pela maioria das infecções parasitárias que afetam os humanos. As denominadas protozooses são causadas por cerca de 10.000 espécies conhecidas de protozoários, das quais cerca de 30 infectam o homem, e são características das regiões menos desenvolvidas do planeta, onde os níveis de escolaridade e de saneamento básico são baixos. Nessas áreas, as protozooses geralmente são endêmicas, sendo por essa razão vulgarmente conhecidas como doenças de gente pobre. ${ }^{1}$ Dentre as protozooses mais conhecidas se destaca a Malária que está presente, atualmente, em praticamente todas as regiões tropicais e subtropicais do mundo.

Esta doença tem causado muitas perdas humanas, principalmente entre crianças de até 5 anos de idade na África, aonde as estatísticas chegam a ser alarmantes. ${ }^{2}$ Porém, com a globalização crescente das atividades humanas em nosso século e as consequiências do aquecimento global, o problema da malária passa a chamar a atenção de praticamente todos os países, principalmente após relatos de que muitas cepas do protozoário causador da doença têm se tornado resistentes aos medicamentos utilizados atualmente, ${ }^{2}$ bem como devido ao aumento do número de casos da doença entre os chamados países de primeiro mundo. ${ }^{2}$

Apesar do progresso obtido pela Organização Mundial de Saúde no combate à malária até finais da década de 70, ela atualmente é um dos mais sérios problemas mundiais de saúde pública. Esta doença afeta de 300 a 500 milhões de pessoas em todo o mundo causando cerca de 2,5 milhões de mortes anualmente, a maioria entre crianças. Hoje a ameaça é maior em nações na América Latina, África, e grandes áreas da Ásia Meridional e Oceania, ${ }^{3}$ o que significa que aproximadamente $40 \%$ da população mundial corre o risco de desenvolver malária. ${ }^{2} \mathrm{~A}$ malária causa por ano muito mais mortes em valores absolutos que a $\operatorname{AIDS}^{4}{ }^{4} \mathrm{O}$ maior número de ca-

*e-mail: tanos@ime.eb.br sos ocorre na África, onde crianças de até 5 anos de idade, cujo sistema imunológico está ainda em formação, são o grupo de maior probabilidade de morte devido à infecção. Fora da África, os países com maior número de casos da doença são Afeganistão, Bangladesh, Brasil, Burma, Camboja, Colômbia, China, Irã, Índia, Indonésia, México e Filipinas. ${ }^{1}$

A malária é causada por protozoários do gênero Plasmodium transmitidos ao homem por fêmeas de mosquitos do gênero Anopheles infectadas. Somente 4 de aproximadamente 100 espécies desses protozoários são responsáveis por infectar seres humanos: $P$. falciparum; $P$ vivax; $P$. ovale e $P$. malariae, sendo o $P$. falciparum o mais perigoso por causar a forma mais grave de malária, a cerebral, que na maioria dos casos leva à morte. Esta doença se caracteriza por causar febres intermitentes que, dependendo da espécie de plasmódio, ocorrem a cada 2 ou 3 dias, dores de cabeça, dores no corpo, anemia, icterícia e inchaço do fígado e baço. No caso da malária cerebral, o parasita pode também comprometer progressivamente o sistema nervoso central. $\mathrm{O}$ tratamento da malária é complexo, longo e muitas vezes ineficaz devido à reinfecção do paciente, fenômeno muito comum em regiões endêmicas. Isto acontece porque muitas das estratégias sabidamente eficazes para o combate a esta doença são pouco acessíveis nos países endêmicos, como a educação da população de risco (principalmente pessoas pobres), a quimioterapia eficiente, o controle do vetor por meio de inseticidas e o uso de mosquiteiros impregnados com inseticidas para evitar a infecção. ${ }^{3}$ Somando-se a isso o rápido surgimento de cepas do $P$. falciparum resistentes aos antimaláricos atualmente disponíveis, ${ }^{5-8}$ a ineficácia das vacinas ${ }^{3}$ e o desinteresse das grandes indústrias farmacêuticas em desenvolver fármacos baratos e acessíveis contra a doença, ${ }^{4}$ não é difícil entender porque a malária ainda é uma emergência global de saúde pública.

\section{ASPECTOS HISTÓRICOS}

Através de seu impacto direto sobre a saúde e seus efeitos indiretos em fatores como desenvolvimento econômico, migração e conflitos militares, a malária tem sido um sério problema na história da humanidade desde a Antiguidade. Acredita-se que a malária tenha sido a principal causa de morte entre os primatas precursores do Homo sapiens, como os Australopithecus. ${ }^{9}$ Há várias referências na literatura antiga e das civilizações modernas que relatam febres 
malignas intermitentes e calafrios consistentes com os sintomas da malária. Em 2.700 a.C. o Cânon Chinês de medicina, o Nei Ching, já discutia sintomas da malária e as relações entre febres e melancolias prolongadas. ${ }^{9}$ Da mesma forma, manuscritos do século VI a.C. escavados da biblioteca real de Assurbanapoli em Nineve (hoje Iraque) mencionam febres mortais semelhantes à malária que afligiam a população da antiga Mesopotâmia. ${ }^{9}$

Os escritos de vários filósofos da antiguidade como Homero, Aristóteles, Platão, Sócrates, Horácio, Tacitus, Carus, Varro, Chaucer e Pepys, mencionam febres relacionadas à malária. ${ }^{9}$ Os escritos de Shakespeare também mencionam febres que eram, sem dúvida, relacionadas à malária. ${ }^{9}$

O fisiologista grego Hipócrates foi o primeiro a fazer uma conexão entre a proximidade de corpos d'água estagnados e a ocorrência de febres na população local. Os romanos também faziam esta associação e foram os pioneiros na drenagem de pântanos. O termo malária surgiu justamente desta relação entre a doença e os pântanos. A doença passou a ser descrita como ária cattiva ou mal'aria (ar ruim) pelos italianos no século XIV e este termo entrou para a língua inglesa em torno de 200 anos depois. De forma semelhante, os franceses criaram o termo "paludismo", cuja raiz significa pântano, para se referir à malária.

Muitos personagens famosos da história sofreram ou padeceram da febre maligna (provavelmente malária). Santo Agostinho, o primeiro arcebispo de Canterbury, morreu de uma doença, que muito provavelmente era malária, em 597 a.C.; Dante Alighieri, o poeta italiano, morreu de febre maligna em 1321 d.C.; Pedro o grande ficou tão aborrecido com as febres e mortes que afligiram seu exército na Pérsia no início dos anos 1720, que ordenou que eles parassem de comer melões, frutas que ele acreditava estarem causando a doença. ${ }^{10}$

O imperador do sacro império Romano Germânico Carlos V morreu de malária em um monastério em Yuste, Espanha, em 1558; o Papa Sixtos V morreu de febre dos pântanos em 1590, da mesma forma que o seu sucessor, Urbano VII. Durante o Conclave de 1623, 8 cardeais e 30 escribas e secretários morreram de febre induzida por malária, enquanto outras pessoas presentes ficaram doentes. ${ }^{10}$ Na Inglaterra, o rei James I, o rei Charles II e o Cardeal Wolsey sofriam de febres intermitentes consistentes com a malária. ${ }^{10}$

\section{A malária na América}

A malária foi uma das mais disseminadas e debilitantes doenças da América do Norte, impedindo significativamente o desenvolvimento das colônias norte-americanas por alguns anos. ${ }^{11}$ Os ingleses introduziram na América duas espécies de agentes causadores de malária, Plasmodium vivax e Plasmodium malariae, quando fundaram Jamestown, na atual Virgínia, em 1607, mas foi a importação de escravos da África a partir de 1620, que trouxe o Plasmodium falciparum para o continente. ${ }^{12}$ Acredita-se que a decisão de transferir a capital sulista de Jamestwon para Williamsburg, em 1699, foi motivada pelo desejo de escapar dos efeitos da malária. Em 1723 George Hume, um colono escocês escreveu para sua família: "Estou sempre com febres e calafrios... este lugar só é bom para médicos e padres" ${ }^{11}$ Com a expansão das colônias para o interior da América do Norte, a malária foi junto. Nos séculos XVIII e XIX, a malária já era endêmica nas partes sudeste e oeste das colônias norte-americanas. A maior parte dos assentados naquelas regiões considerava inevitável contrair a doença. ${ }^{13} \mathrm{Na}$ Nova Inglaterra, a malária não foi um problema tão grave porque lá os pântanos foram drenados.

No Brasil, a ocupação desordenada da região amazônica, incentivada por diversos órgãos governamentais, a construção de usinas hidroelétricas, o desenvolvimento de projetos agropecuários e a instalação de inúmeros garimpos, provocaram um incremento consi- derável da transmissão da malária no início da década de $1980 .{ }^{14-19}$ Nesta época, 97,5\% dos casos de malária registrados no Brasil eram oriundos da região amazônica. Desde então, o número de novos casos de malária triplicou, passando de 52.469, em 1970, para 169.871, em 1980. Destes, 34,8\% ocorreram em Rondônia, 22,4\% no Pará, $11,3 \%$ no Maranhão, $9 \%$ no Mato Grosso e $8 \%$ em Roraima. ${ }^{20}$ Fora da Amazônia, o maior número de casos foi observado em Goiás, seguindo-se Paraná, São Paulo e Mato Grosso do Sul, estados que receberam a maior proporção de casos oriundos da região norte do país. ${ }^{20} \mathrm{Na}$ década de 90 , a malária aumentou de forma preocupante, atingindo sua maior incidência, com 632.813 casos, dos quais 99,7\% na Amazônia Legal (composta pelos estados do Acre, Amapá, Amazonas, Maranhão, Mato Grosso, Pará, Rondônia, Roraima e Tocantins). Diante desta gravíssima situação, no ano 2000 o Ministério da Saúde intensificou suas ações em parceria com os municípios e estados amazônicos. Em 2002, observouse o maior declínio de casos de malária dos últimos 40 anos. Foram 349.896 casos, uma queda de 45,1\% em relação a 1999. Em 2003, o número de casos continuou diminuindo, entretanto, com menor intensidade, uma redução de 13\%. Em 2004 voltou-se a observar um aumento da doença no Brasil, com 459.000 casos e esse número continuou a aumentar em 2005 quando foram registrados 597.000 casos, com dezenas de mortes. Em 2006, embora tenha havido uma pequena redução em relação a 2005, ainda foram registrados alarmantes 546.000 casos de malária no Brasil. ${ }^{21}$

\section{A malária e os militares}

A malária teve grande impacto também sobre as campanhas militares ao longo da história, desde a Antiguidade. Seus efeitos debilitantes podem geralmente causar mais danos que o inimigo. Em 1910, o Coronel C. H. Melville, professor de higiene do Royal Army Medical College em Londres, e autor de um capítulo no livro de Ronald Ross "The Prevention of Malaria", escreveu a seguinte frase: "A história da Malária na guerra se confunde com a história da guerra propriamente dita". ${ }^{22}$

Acredita-se que Alexandre o grande morreu de malária no auge de seu poder. $\mathrm{O}$ general macedônio que conquistou quase todo o mundo conhecido de sua época contraiu a febre maligna quando partia com seu exército, no início de junho de 323 a.C., para mais uma campanha, e morreu aos 33 anos de idade. ${ }^{22}$

Em muitas ocasiões a malária impediu a invasão e/ou conquista de Roma ao longo da história. Alaric, rei dos Góticos e Átila o Uno no Século IV, o general romano Belisarius do império romano do oriente em 536, Otto I em 964 e Frederico I, Henrique II e Henrique IV na Idade Média, todos tiveram seus exércitos dizimados ou seriamente enfraquecidos pela malária ao tentar conquistar a cidade..$^{22}$

A malária também foi usada como arma biológica por Napoleão contra os britânicos em Walcheren nos Países Baixos. Em 30 de julho de 1809, uma força britânica de 39.000 homens desembarcou em Walcheren com o objetivo de auxiliar os austríacos em sua guerra contra Napoleão e atacar a frota francesa em Flushing (Vlissingen). Napoleão deliberadamente inundou o interior da Holanda permitindo, assim, a disseminação da malária. "Não vamos oferecer resistência aos ingleses além da febre que logo vai devorá-los", disse o general francês. A expedição britânica tornou-se tão debilitada entre agosto e outubro daquele ano que foi incapaz de sustentar a campanha militar. No início de agosto eram 700 homens doentes mas em 3 de setembro, mais de 8.000 estavam no hospital. Em fins de outubro, 9.000 homens estavam doentes e em torno de seis meses depois, a doença persistia com 11.000 homens ainda doentes. Quando a expedição terminou, em fevereiro de 1810 , a febre tinha tirado de combate mais de $40 \%$ dos homens. ${ }^{22}$ 
Durante a Guerra Civil Norte Americana (1861-1865), 10.000 combatentes morreram de malária e houve mais de 1,3 milhão de casos da doença registrados entre as tropas dos Confederados e da União. ${ }^{9,23}$ Foi estimado que $50 \%$ dos soldados brancos e $80 \%$ dos negros contraíam malária anualmente. ${ }^{22}$

A campanha francesa em Madagascar, em 1895, teve apenas 13 mortos em combate, mas 4.000 mortos por malária. ${ }^{22}$

Na Primeira Guerra Mundial os exércitos britânico, francês e alemão ficaram imobilizados pela malária por 3 anos na Macedônia. Em uma ocasião, respondendo a uma ordem de ataque, um desesperado general francês telegrafou a Paris: "Mon armee est immobiliseé dans les hopitaux" (Meu exército está imobilizado nos hospitais). ${ }^{23}$ Quase $80 \%$ dos 120.000 franceses naquela área foram hospitalizados com malária. Em uma força média britânica de 124.000 homens houve 162.512 internações em hospitais por causa da malária durante o período de 1916 a 1918, em contraste com os 23.762 mortos, feridos, aprisionados e desaparecidos em ação. ${ }^{22}$

Na Segunda Guerra Mundial o exército dos Estados Unidos sozinho registrou mais de 500.000 casos de malária, enquanto que a marinha registrara $90.000 .{ }^{23,24} \mathrm{O}$ General Douglas MacArthur, comandante do teatro de operações no Pacífico Sul, disse em relação à malária: "Esta será uma longa guerra se para cada divisão enfrentando o inimigo eu tiver que contar com uma segunda divisão no hospital com malária e ainda uma terceira convalescente desta doença". ${ }^{24} \mathrm{O}$ desenvolvimento e uso de antimaláricos sintéticos e inseticidas residuais, como o DDT, foram grandes contribuições para o combate à malária durante a Segunda Guerra Mundial. A dependência da quinina como o único antimalárico foi aliviada e muitos novos antimaláricos, como cloroquina, amodiaquina, primaquina, proguanil e pirimetamina, entraram em uso. ${ }^{22}$

A malária também teve um grande impacto sobre as tropas norte americanas na Coréia (1950-53), onde os hospitais ficaram lotados e chegaram a registrar 629 casos por semana. No Vietnam (1962-75) a malária causou mais baixas ao exército americano que os projéteis dos vietcongues, especialmente no início do conflito. A doença reduziu o poder de combate das tropas em 50\%. No fim de 1965 , quase $10 \%$ dos soldados americanos tinham a doença. Foram registrados 80.000 casos de 1965 a 1971 , mas a taxa de mortalidade geral foi de apenas 1,7 para cada 1.000 , graças ao rápido diagnóstico e tratamento dos doentes. ${ }^{23}$

Mesmo nas campanhas militares mais recentes os norte americanos ainda sofreram com a malária. Na operação "Restaurando a Esperança” na Somália (1992-1994), a malária foi a principal causa de baixas entre as tropas americanas. No Afeganistão, no Iraque e na Libéria (2001-03) foram registrados mais de 200 casos da doença com 53 mortes. ${ }^{22}$

Atualmente, todas as nações que mantêm forças militares em áreas endêmicas sofrem com a malária. Nas unidades militares do exército brasileiro em operação na região amazônica, a malária tem sido muitas vezes o maior responsável por casos de baixas em hospital e afastamentos para tratamento de saúde. ${ }^{25}$ Desta forma, na atualidade, a malária é um dos maiores obstáculos para quaisquer tipos de atividades que o Brasil queira executar na Amazônia, especialmente para as forças armadas, os colonos e suas famílias.

A malária também tem sido um problema para os soldados brasileiros envolvidos em missões de paz das Nações Unidas. Na missão MONUA em Angola, de 1995 a 1996, dentre os 439 soldados brasileiros envolvidos, foram registrados 78 casos e 3 mortes mesmo entre indivíduos que estavam fazendo uso de quimioprofilaxia. ${ }^{26}$ Na missão MINUSTAH para a estabilização do Haiti que teve início em junho de 2004, já foram registrados mais de 20 casos de malária entre os brasileiros. ${ }^{27}$

A relação íntima entre malária e guerra tem sido um grande incentivo para a busca constante por novos antimaláricos também en- tre os militares. O centro médico da Marinha dos Estados Unidos (The Navy Medical Research Center), o Instituto de Pesquisas Walter Reed do Exército dos EUA (Walter Reed Army Institute of Research) e o Instituto de Pesquisas contra Doenças Infecciosas das Forças Armadas dos EUA (U. S. Army Medical Research Institute of Infectious Diseases) estão continuamente engajados em pesquisas na busca por novos fármacos e vacinas contra malária. ${ }^{22}$ Em média, o Exército Americano aplica cerca de US\$10.000.000,00 por ano nas pesquisas relacionadas com a malária.

\section{ASPECTOS CLÍNICOS}

Os sintomas da malária são febre, calafrios, cefaléia, vômito, anorexia, fadiga, diarréia e anemia. Se não tratada adequadamente a doença pode apresentar complicações como edema pulmonar, complicações renais, icterícia e obstrução de vasos sangüíneos no cérebro (nos casos graves da doença), situação que poderá levar à morte do indivíduo.

As infecções malariais que ocorrem no homem são conhecidas conforme as espécies do protozoário envolvido. Deste modo, tem-se: a malária falciparum, também conhecida como malária grave ou maligna que ocorre principalmente na África subsaariana, mas também está presente em todas as regiões tropicais do mundo; a malária vivax, chamada de malária benigna, muito comum na América do Sul e que também é a forma de malária mais largamente distribuída e observada em regiões temperadas do mundo; a malária malariae, que tem a mesma distribuição geográfica da malária falciparum, embora seja muito menos prevalente e ocorra em zonas mais restritas, e a malária ovale que ocorre quase exclusivamente na África. ${ }^{28}$

A malária falciparum tem um período de incubação de 1 a 3 semanas (média de 12 dias), sendo também a forma mais grave da doença, pois leva um maior número de doentes à morte.

A malária vivax, também conhecida como "terçã” benigna, pois é caracterizada pela intermitência dos ataques paroxísticos da doença provenientes da infecção eritrocítica que ocorrem a cada 3 dias, é a forma de malária mais freqüente no Brasil, tendo um período de incubação de 1 a 4 semanas (média de 2 semanas).

A malária malariae é a forma "quartã" da doença, com intermitência a cada 4 dias e um período de incubação de 2 a 4 semanas (média de 3 semanas). Além dos sintomas gerais, esta forma da doença pode também causar nefrites.

A malária ovale, que tem um período de incubação de 9 a 18 dias (média de 14 dias), é basicamente uma forma terçã da doença, que ocorre quase exclusivamente na África. ${ }^{28}$

\section{O ciclo de vida do parasita}

Em 1846, o fisiologista italiano Giovanni Rasori propôs que um parasita seria o responsável pela febre e outros sintomas associados à malária, mas foi em 1880 que Charles Louis Alphonse Laveran, um oficial médico do exército francês, observou, pela primeira vez, parasitas vivos tirados do sangue de um soldado francês infectado com malária na Algéria, ${ }^{28}$ além de descobrir as quatro formas do parasita: anel, trofozoíto, esquizonte e gametócito. Seis anos depois da descoberta de Laveran, Camillo Golgi descobriu o desenvolvimento assexuado e mostrou que o início da febre coincidia com a ruptura das hemácias e a liberação dos parasitas. Em 1891, Dimitri Romanowsky usou uma combinação de eosina e azul de metileno para colorir os núcleos e o citoplasma do parasita, facilitando muito os diagnósticos. William George MacCallum e Eugene L. Opie, em 1897, encontraram o parasita da malária no estômago de mosquitos. Em 20 de agosto de 1897, Ronald Ross demonstrou definitivamente que a transmissão da malária se dava através do 
mosquito. ${ }^{29}$ Estes descobrimentos incentivaram a pesquisa sobre este parasita, sendo que alguns dos maiores avanços no entendimento do complexo ciclo de vida dos parasitas da malária foram feitos pelos italianos, na virada do século XIX. Em 1898, Giovanni Battista Grassi, Amico Bignami e Guiseppe Bastianelli documentaram a transmissão de parasitas da malária humana em Anopheles claviger e logo depois descreveram os estágios de desenvolvimento do Plasmodium falciparum e do Plamodium vivax. ${ }^{28}$

Um acalorado debate envolveu a descoberta de que os parasitas da malária são transmitidos por mosquitos anofelinos. Grassi e seus colaboradores, assim como Sir Ronald Ross, um médico militar britânico trabalhando na Índia, estavam pesquisando o assunto simultaneamente e foram influenciados por outro cientista britânico, Patrick Manson, que defendeu a hipótese de que os mosquitos eram responsáveis pela transmissão da doença. Usando malária de aves como modelo, Ross foi o primeiro a demonstrar o ciclo da malária em mosquitos. Mas foram os italianos que documentaram definitivamente que apenas mosquitos Anopheles podem transmitir malária para o ser humano. Uma clássica monografia de Grassy, em 1900, detalha o ciclo completo de desenvolvimento do parasita nestes mosquitos. Em 1902, Ross ganhou o prêmio Nobel de medicina por seu trabalho com malária. ${ }^{28}$

Os protozoários do gênero Plasmodium têm um ciclo de vida dividido entre um hospedeiro vertebrado e um inseto vetor. Segundo Rey, ${ }^{16}$ os Plasmodium falciparum, vivax e ovale são parasitas exclusivos do homem enquanto que o $P$. malariae seria capaz também de infectar chimpanzés em condições naturais. O vetor é sempre um mosquito fêmea do gênero Anopheles, embora das 380 espécies conhecidas de mosquitos desse gênero, apenas 60 possam transmitir a doença. ${ }^{28}$

O ciclo de vida de todas as espécies de Plasmodium (Figura 1) é complexo. A infecção em humanos começa com a picada de uma fêmea infectada do mosquito. Enquanto ela se alimenta, esporozoítos saem das suas glândulas salivares, entram na corrente sanguínea e rapidamente invadem as células do fígado (hepatócitos). Este processo é tão rápido que em torno de 30 min após a infecção, já não há mais esporozoítos na corrente sanguínea. Nos 14-16 dias seguintes, os parasitas, que estão em sua fase hepática, se diferenciam e sofrem multiplicação assexuada dando origem a dezenas de milhares de merozoítos que eclodem na ruptura de cada hepatócito. Cada merozoíto assim formado, então, invade um eritrócito, onde passa por mais uma etapa de multiplicação produzindo de 12 a 16 merozoítos por esquizonte (glóbulo vermelho contaminado). A du-

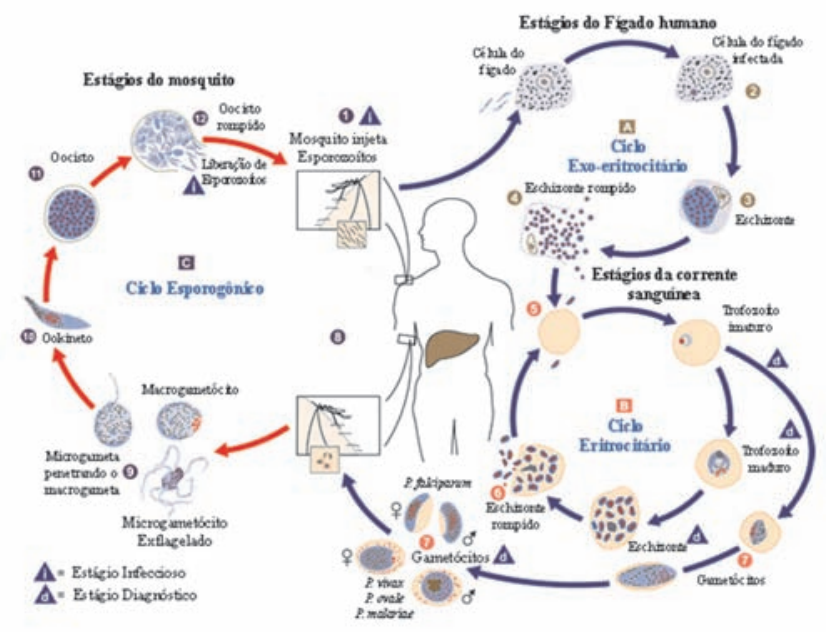

Figura 1. Ciclo de vida das espécies de Plasmodium causadoras de malária em humanos. Adaptado da ref. 30 ração deste estágio eritrocítico depende da espécie do parasita, sendo de 48 h para $P$. falciparum, $P$. vivax, e $P$. ovale e de 72 h para $P$. malariae. ${ }^{30}$

As manifestações clínicas da malária, febres e calafrios, são associadas com a ruptura sincronizada dos eritrócitos infectados. A maior parte dos merozoítos liberados na eclosão dos esquizontes invade outros eritrócitos dando origem a outros esquizontes. Alguns, todavia, se diferenciam em formas sexuadas masculinas e femininas chamadas de microgametócitos e macrogametócitos, respectivamente. Estes gametócitos permanecem na corrente sanguínea até serem ingeridos por uma fêmea do Anopheles numa eventual refeição de sangue. Dentro do intestino delgado do mosquito, os gametócitos sofrem rápida divisão celular, produzindo 8 microgametas flagelados cada um, os quais fertilizarão os macrogametas formando assim os ookinetos (macrogametas fecundados). Os ookinetos atravessam a parede do intestino e formam cistos em sua parte exterior, chamados de oocistos. Em poucos dias os oocistos sofrem a esporogenia e se rompem liberando centenas de esporozoítos que, eventualmente, migrarão para as glândulas salivares do mosquito prontos para serem injetados em outro hospedeiro vertebrado.

Uma vez injetadas no hospedeiro, todas as espécies de Plasmodium penetram os hepatócitos. Todavia, $P$. falciparum e $P$. malariae começam imediatamente a esquizogonia, enquanto esporozoítos de $P$. ovale e $P$. vivax podem ter esse início retardado, resultando em hipnozoítos dormentes. Algumas linhagens parecem consistir apenas de esporozoítos retardados, o que pode aumentar o período de incubação em até 10 meses para o $P$. vivax. Os gametócitos produzidos no ataque primário parecem conter toda a informação genética requerida para criar esporozoítos em tempos de ativação diferentes. O mesmo parece acontecer para gametócitos produzidos quando os hipnozoítos se tornam ativos. ${ }^{31}$ Um mosquito transfere em sua picada, em torno de $10 \%$ de seus esporozoítos para os vasos capilares ou tecidos perivasculares. A partir daí os esporozoítos têm que iniciar a invasão das defesas do hospedeiro, possivelmente se ligando a proteínas plasmáticas para se camuflar. ${ }^{32}$ Alguns são destruídos pelos macrófagos ou por anticorpos específicos em indivíduos imunes, mas em indivíduos não imunes eles atingem os hepatócitos e iniciam a esquizongenia ou se tornam hipnozoítos, dependendo de seus tempos de ativação.

\section{A QUIMIOTERAPIA ANTIMALÁRICA}

Atualmente os fármacos antimaláricos são baseados em produtos naturais ou compostos sintéticos produzidos a partir da década de 40 . Esses fármacos são específicos para cada etapa do ciclo de vida do Plasmodium. Existem fármacos chamados eritrocíticos, que atuam nas formas presentes nos eritrócitos do homem, os fármacos gametocíticos que matam as formas sexuadas do parasita (gametócitos) de um indivíduo infectado, de forma que quando esse é picado por outro mosquito se evita a transmissão da doença para o inseto e assim a disseminação da doença para outras pessoas e, por último, os fármacos esporonticidas (ou esporoitocidas), que atuam contra esporozoítos e são capazes de matar os parasitas assim que eles entram na corrente sangüínea, após a picada do mosquito, ou ainda destruí-los quando são liberados pelos esquizontes hepáticos ou sanguíneos. É importante mencionar que os fármacos antimaláricos podem atuar contra mais de uma forma do protozoário e serem efetivos contra uma espécie, mas totalmente ineficazes contra outras.

Os principais fármacos antimaláricos são classificados, de acordo com o modo de ação, em dois grandes grupos: $\mathrm{O}$ primeiro grupo inclui os alcalóides derivados da cinchona, as aminoquinolinas e as acridinas. Acredita-se que esses fármacos podem interferir no me- 
tabolismo da glicose em diferentes pontos ${ }^{16}$ e também na habilidade do parasita de digerir a hemoglobina, impedindo, assim, que ele se alimente ou intoxicando-o com altos níveis de ferriprotoporfirinaIX, que é um subproduto tóxico da digestão da hemoglobina. ${ }^{33,34}$

$\mathrm{O}$ segundo grupo inclui as pirimidinas e biguanidas e envolve a interferência na síntese do ácido tetra-hidrofólico, importante cofator no processo de síntese de DNA e de aminoácidos. ${ }^{35}$ Fármacos pertencentes a estes dois grupos serão discutidos a seguir.

\section{Principais antimaláricos ${ }^{1,36}$}

Índios sul americanos já usavam a casca da Chichona, uma planta nativa da América do Sul, como um remédio tradicional para a malária muito antes que qualquer tratamento estivesse disponível na Europa. Em 1639, missionários jesuítas levaram consigo algumas cascas dessa planta para a Europa, onde elas se tornaram o tratamento principal para as febres. Todavia, foi apenas em 1820 que os químicos franceses Pierre Joseph Pelletier e Joseph Bienaime Caventou identificaram o alcalóide quinina (Figura 2A) como o ingrediente ativo da casca da cinchona. ${ }^{36}$ Logo após sua descoberta, a demanda e uso da quinina espalharam-se rapidamente pela Europa, América do Norte e Ásia. Até meados do século passado, a quinina era o principal quimioterápico utilizado no combate à malária. Seu uso só foi reduzido em função da sua alta toxicidade e com o surgimento de cepas de P. falciparum resistentes, mas sua importância voltou a aumentar na atualidade, em função do surgimento de resistência aos outros fármacos.

A quinina faz parte da família das quinolinas que incluem as 4 aminoquinolinas, as 8-aminoquinolinas e os álcoois quinolínicos. Estes compostos são ativos contra formas eritrocíticas de $P$. falciparum e $P$. vivax. $\mathrm{O}$ mais eficaz dentre esses fármacos foi a cloroquina (Figura 2B), uma das substâncias antimaláricas mais utilizadas para a supressão e profilaxia da malária em muitas regiões endêmicas. Foi o fármaco preferido até o surgimento da resistência do parasita. Atua como um agente esquizonticida e raramente produz sérios efeitos colaterais no tratamento profilático da doença. Infelizmente, foi o uso profilático que levou à resistência, que ocorre em todos os países endêmicos, com exceção de certos países da América Central. ${ }^{37}$

A mefloquina (Figura 2C) requer menos que um décimo da dose de quinina para o tratamento da malária e tem sido utilizada no combate ao Plasmodium falciparum resistente à cloroquina. Complicações gastrintestinais, tonturas e efeitos psicológicos são os principais efeitos colaterais, geralmente temporários, mas que fazem com que sua administração não seja recomendada para o tratamento de pacientes com histórico de epilepsia ou desordens psiquiátricas. Apesar deste fármaco ser relativamente novo, já foram relatados casos de resistência.

A amodiaquina e a hidróxi-cloroquina (Figuras 2D e 2E) têm sido duas alternativas para o tratamento da malária causada por cepas de $P$. falciparum resistentes à cloroquina. Entretanto, esses medicamentos são menos efetivos. Além disso, a amodiaquina é mais tóxica que a cloroquina.

O mecanismo de ação preciso das quinolinas ainda não é completamente entendido. As hipóteses sobre seu modo de ação incluem: ligação direta ao grupo heme da hemoglobina; inibição de uma ferriprotoporfirina-IX polimerase não identificada; inibição da fosfolipase vacuolar; inibição da síntese de proteínas e interação com o DNA. Todavia, o principal modo de ação parece estar relacionado ao acúmulo destas bases fracas no lisossomo ácido do parasita e a ligação à ferriprotoporfirina-IX (grupo heme da hemoglobina), evitando, assim, a polimerização desta substância pela ferriprotoporfirina-IX polimerase e interrompendo o mecanismo de detoxificação do parasita, através do qual ele converte a

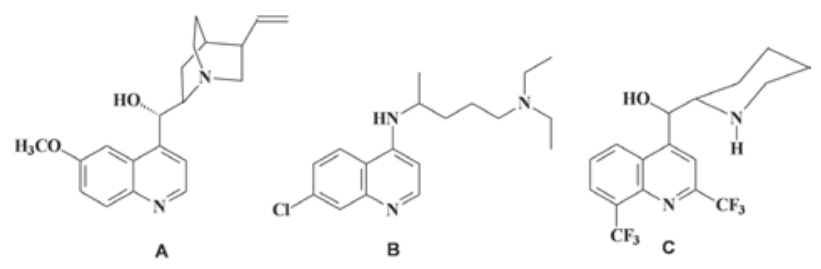

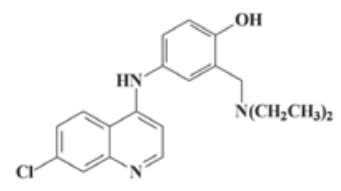

D
E

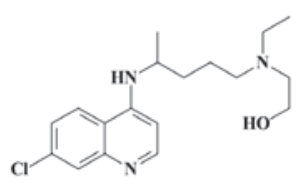

Figura 2. Estruturas dos álcoois quinolínicos: Quinina (A) e Mefloquina (C) e das 4 - aminoquinolinas: Cloroquina (B), Amodiaquina (D) e Hidróxicloroquina $(E)$

ferriprotoporfirina-IX, um subproduto tóxico da digestão da hemoglobina, em hemozoína, um polímero inerte, insolúvel e não tóxico. $\mathrm{O}$ conseqüente acúmulo de ferriprotoporfirina-IX dentro dos vacúolos do parasita, o leva à morte. ${ }^{33,34}$

Algumas 8-aminoquinolinas são eficazes contra formas teciduais primárias e secundárias do parasita, assim como nos seus estágios sexuados. Constituem a única classe de fármacos gametocidas. A pamaquina (Figura 3A) e a primaquina (Figura 3B) são dois exemplos. A primeira, sintetizada na Alemanha durante a década de 20, é o mais antigo agente antimalárico do grupo das 8-aminoquinolinas. A primaquina tem sido amplamente utilizada contra hipnozoítos (formas exoeritrocitárias) em P. vivax e P. ovale. É o mais utilizado dos fármacos desse grupo, sendo geralmente co-administrada com um agente esquizonticida sangüíneo, como a cloroquina (Figura 2B), a amodiaquina (Figura 2D) ou a pirimetamina (Figura $6 \mathrm{~A})$, este último um antagonista do folato.
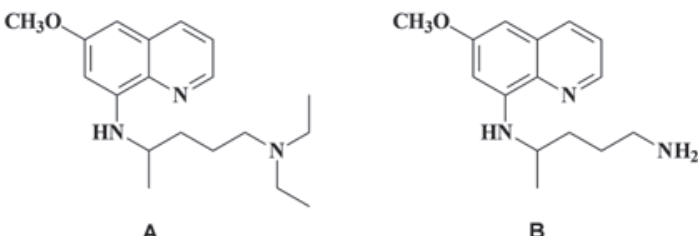

Figura 3. Estruturas da pamaquina $(A)$ e da primaquina (B)

Um derivado do fenantreno, a halofantrina (Figura 4), é efetivo contra a malária resistente à cloroquina e tem sido avaliado para o uso humano, apresentando distúrbios gastrintestinais como seus principais efeitos colaterais. A resistência do parasita a esse medicamento, além da ocorrência de casos de resistência cruzada com a mefloquina, já foram relatados. ${ }^{37}$

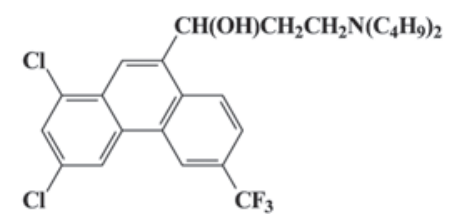

Figura 4. Estrutura da halofantrina

Antagonistas do folato podem atuar como excelentes esquizonticidas no sangue. Entretanto, os parasitas da malária têm desenvolvido resistência a esses fármacos. Muitos dos antifolatos são tóxicos ao homem e apresentam pouca tolerância oral e para a 
absorção, mas podem ser usados no tratamento de diversas doenças, inclusive câncer. ${ }^{38}$ Esses fármacos são divididos em dois grupos de acordo com seus mecanismos de ação. O primeiro grupo (antifolatos do tipo I) inclui compostos que são competidores do ácido para-aminobenzóico (PABA), interrompendo a formação do ácido di-hidrofólico, necessário para a síntese de ácidos nucléicos, através da inibição da di-hidropteroato sintase. Dois exemplos desta classe são as sulfonas e as sulfonamidas. A dapsona (Figura 5A) é a mais conhecida entre as sulfonas antimaláricas. Todavia, sua toxicidade tem desencorajado sua utilização. As sulfonamidas antimaláricas incluem a sulfadoxina (Figura 5B), a sulfadiazina (Figura 5C) e o sulfaleno (Figura 5D). Compostos desta família apresentam fácil absorção, mas difícil excreção pelo organismo.
A

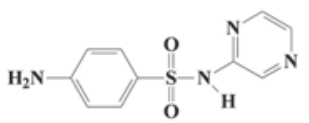

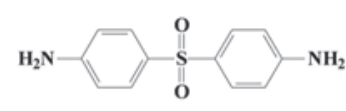

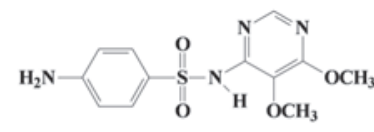

B

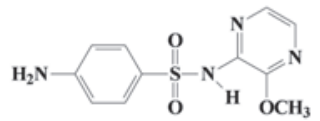

Figura 5. Estruturas das sulfas: Dapsona (A); Sulfadoxina (B), Sulfadiazina (C) e Sulfaleno $(D)$

O segundo grupo de antagonistas do folato (antifolatos do tipo II) liga-se preferencialmente e seletivamente à enzima di-hidrofolato redutase-timidilato sintase (DHFR-TS) do parasita. Esta inibição interfere na habilidade do Plasmodium em converter o ácido dihidrofólico em tetra-hidrofolato, cofator importante no processo de síntese de ácidos nucléicos e aminoácidos. Esta enzima, que teve sua estrutura determinada recentemente por métodos de difração de raios-X, ${ }^{39}$ tem sido alvo de diversos estudos por modelagem molecular visando o planejamento de novos antimaláricos ${ }^{40-44} \mathrm{e}$, mais recentemente, outra enzima deste ciclo, a serina hidroximetiltransferase (SHMT) também tem sido vista na literatura como potencial alvo para novos antimaláricos, apesar da sua grande semelhança seqüencial e estrutural com a enzima humana. ${ }^{45,46}$

Inibidores da DHFR são potentes agentes esquizonticidas que atuam sobre formas assexuadas do parasita. Membros dessa classe de antifolatos incluem a pirimetamina (Figura 6A) e a trimetoprima (Figura 6B). A pirimetamina atua contra o P. falciparum de forma lenta, não sendo indicada para o tratamento da fase aguda da malária. A combinação da pirimetamina com a sulfadoxina (Figura 5B), chamada de Fansidar® (patenteado pela Roche), mostrou-se útil. Além disso, a pirimetamina foi combinada com outros fármacos, como a dapsona (Figura 5A), o sulfaleno (Figura 5D) e a cloroquina (Figura 2B). A trimetoprima (Figura 6B) tem um modo de ação similar à pirimetamina, e por ser também um fármaco de ação lenta, tem sido administrada em combinação com fármacos de ação mais rápida, como o sulfaleno (Figura 5D).

As biguanidas têm um mecanismo de ação semelhante ao da pirimetamina (Figura 6A) e trimetoprima (Figura 6B). O mais im-
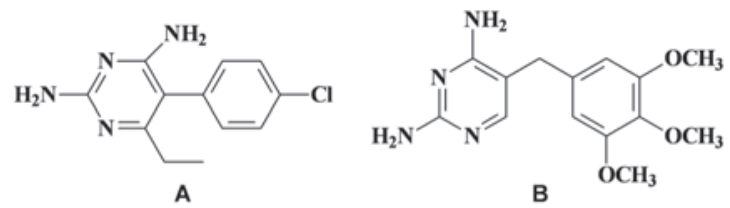

Figura 6. Estruturas da pirimetamina (A) e da trimetoprima (B) portante destes compostos, o proguanil (Figura 7A) é um pró-fármaco que é metabolicamente ciclizado a cicloguanil (Figura 7B). Este composto é pouco tóxico e é útil como agente profilático, destruindo parasitas durante a passagem para a corrente sangüínea antes que invadam as hemácias. Esse fármaco tem sido utilizado juntamente com a cloroquina principalmente em viajantes não-imunes à doença e em áreas onde o nível de resistência a essa última é moderado.

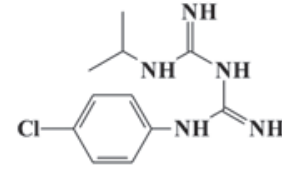

A

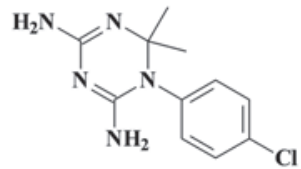

B
Figura 7. Estruturas do proguanil (A) e do cicloguanil (B)

Quinonas e naftoquinonas foram utilizadas como antimaláricos durante a Segunda Guerra, com eficiência inferior à cloroquina. Ainda assim, devido à resistência do protozoário frente à cloroquina (Figura 2B), compostos desse tipo, como a menoctona (Figura 8), estão sendo reavaliados.

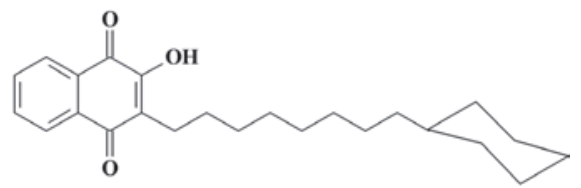

Figura 8. Estrutura da menoctona

A artemisinina, ou qinghaosu (Figura 9), é um produto natural extraído de uma erva medicinal chinesa a Artemisia annua ou Qing Hao como é conhecida pelos chineses. Esta planta foi documentada em 340 a.C. pelos chineses como tratamento para as febres em um livro médico chamado de "Zhou Hou Bei Ji Fang" (ou "Manual de prescrições para tratamentos de emergência"). ${ }^{47}$ A artemisinina foi isolada pela primeira vez na década de 70, mas pesquisas com extrato de Artemisia annua já faziam parte de um projeto militar chinês secreto. O projeto 523, iniciado em 1967 e que tinha como propósito ajudar os militares vietnamitas a combater a malária durante a guerra do Vietnam, obtendo, assim, uma vantagem estratégica contra os norte-americanos. ${ }^{22}$

A partir da artemisinina, já foram sintetizados vários análogos com variadas atividades famacocinéticas como o artesunato de sódio, a diidroartemisinina, o arteéter e o arteméter (Figura 9). Estes compostos sesquiterpênicos apresentam uma ponte de peróxido sobre o anel de 7 membros e são esquizonticidas sanguíneos. Estes compostos também possuem atividade gametocida, que limita a transmissão para outros hospedeiros, reduzindo assim o espalhamento de formas resistentes. Todavia, ainda não se sabe se este efeito é devido à sua rápida ação sobre as formas sanguíneas do parasita, impedindo o surgimento dos gametócitos, ou se existe mesmo um efeito sobre a forma sexuada. Além disto, estas substâncias são ativas contra cepas de Plasmodium resistentes a todos os outros fármacos e têm aplicação crescente no tratamento de malária falciparum aguda, sobretudo no sudeste asiático. Apesar do sucesso dessa família de fármacos, já há relatos da ocorrência de resistência a esses compostos em algumas províncias da China. ${ }^{48}$

Vários estudos mostram que a ponte de endoperóxido destes compostos pode ser clivada pela redução com íon ferroso presente no grupo heme da hemoglobina ou de origem exógena. Esta clivagem forma um ou mais radicais livres que podem alquilar ou modificar covalentemente proteínas dos parasitas. Outros experimentos indicam que o mecanismo de ação é similar ao das quinolinas, onde os 
fármacos se acumulam no vacúolo digestivo do parasita e interferem na formação da hemozoína. ${ }^{48}$

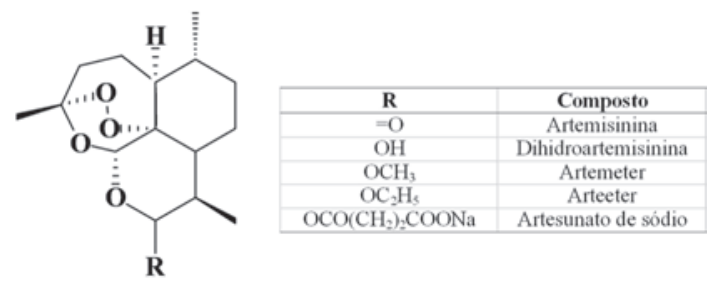

Figura 9. Estruturas da artemisinina e seus derivados

\section{RESISTÊNCIA AOS ANTIMALÁRICOS}

A resistência à quimioterapia é um dos maiores problemas no controle da atual epidemia de malária. Ela se deve ao princípio da evolução das espécies, onde a presença de fármacos (ou pressão dos fármacos) serve como processo de seleção natural dos parasitas resistentes dentro do hospedeiro. ${ }^{49}$

A resistência tem maior probabilidade de ocorrer quando o número de parasitas em um indivíduo é alto, a transmissão é baixa e a pressão do farmaco é intensa. ${ }^{50} \mathrm{~A}$ utilização de um único fármaco no tratamento ocasiona uma seleção e espalhamento de parasitas mutantes resistentes ao fármaco. A longo prazo, o uso de múltiplos fármacos leva ao aparecimento de cepas de parasitas multiresitentes. ${ }^{51,52} \mathrm{O}$ uso de coquetéis de fármacos que atingem alvos diferentes no parasita diminuem a probabilidade do surgimento de cepas resistentes. Um exemplo de coquetel para a malária é o Fansidar ${ }^{\circledR}$, onde a sulfadoxina inibe a di-hidropteroato sintase, enquanto que a pirimetamina inibe a di-hidrofolato redutase. A inibição simultânea das duas enzimas diminui a probabilidade de aparecimento de microorganismos resistentes.

A grande capacidade de adaptação dos parasitas da malária evidencia-se na rapidez com que se desenvolveu, particularmente em $P$. falciparum, a resistência a praticamente todos os antimaláricos sintéticos desenvolvidos a partir de $1940 .^{53} \mathrm{O}$ uso inadequado dos medicamentos e/ou a administração de fármacos com baixa qualidade também contribuem para o surgimento de resistência. ${ }^{54}$

Acredita-se que a primeira ocorrência de cepas de P. falciparum cloroquina-resistentes ocorreu no final dos anos 50, no Sudeste Asiático e também na América do Sul. Atualmente, cepas com esta característica estão espalhadas por todas as áreas endêmicas do mundo e uma diminuição da sensibilidade à quinina e à mefloquina tem sido relatada na América do Sul. ${ }^{54}$

Também os antifolatos, que estão entre os antimaláricos mais utilizados no passado, têm perdido sua eficácia devido ao surgimento de resistência. Primeiro foi o proguanil (paludrina) na Malásia, Indonésia, Nova Guiné e Assam e depois a pirimetamina, na África. Como eram antifolatos, parecia que a resistência estaria relacionada com seus mecanismos de ação. Mas a partir de 1961, constatou-se o surgimento de resistência do $P$. falciparum à cloroquina no Brasil, na Colômbia, na Venezuela, no Panamá, no Peru e no Sudeste Asiático. Depois de 1970, o problema acabou por estenderse ao Sul da Ásia e, mais recentemente, à África. ${ }^{16}$

Pirimetamina e cicloguanil, dois dos mais importantes antifolatos do tipo II, são hoje quase ineficazes no tratamento da malária na América do Sul. Estes fármacos eram utilizados principalmente em combinação com as sulfonas ou sulfonamidas. A combinação pirimetamina-sulfadoxina (Fansidar ${ }^{\circledR}$ ) era uma das principais combinações de escolha para o tratamento da malária no continente até 1979, mas praticamente perdeu seu efeito a partir dos anos 80 devido ao rápido surgimento de cepas do parasita resistentes. ${ }^{6,55-57}$
A capacidade do parasita de desenvolver resistência aos antimaláricos e a ausência de uma vacina para controlar a doença asseguram a permanência do problema global que a malária representa. ${ }^{58}$

A utilização de fármacos e esquemas de tratamentos seguros e eficazes são pressupostos básicos para a efetividade e alcance da meta de redução da morbimortalidade por malária, principalmente considerando que a estratégia atual de controle está baseada no diagnóstico precoce e no tratamento adequado e oportuno dos casos. Nesse sentido, foi criada, em 2001, a Rede Amazônica de Vigilância da Resistência às Drogas Antimaláricas (RAVREDA) ${ }^{21}$ com o objetivo de monitorar a resistência aos fármacos antimaláricos em toda Região Amazônica, utilizando protocolos padronizados para avaliação da suscetibilidade dos parasitas aos medicamentos. Fazem parte da rede amazônica Bolívia, Brasil, Equador, Colômbia, Guiana, Peru, Suriname e Venezuela. O projeto é coordenado regionalmente pela Organização Pan-Americana da Saúde (OPAS) e apoiado com recursos da United States Agency for International Development (USAID). No Brasil, o responsável pelo projeto é a Secretaria de Vigilância em Saúde do Ministério da Saúde. ${ }^{21}$

\section{CONSIDERAÇÕES FINAIS}

No presente trabalho, procurou-se fazer uma curta revisão dos aspectos históricos relevantes relacionados à malária, bem como dos principais quimioterápicos em uso hoje em dia no combate a esta doença.

Como foi visto, a malária aflige a humanidade desde a Antiguidade, tendo vitimado muitos personagens importantes da nossa história e muitas vezes mudado o rumo dos acontecimentos. Reis, rainhas, líderes religiosos, líderes militares, pensadores e até papas foram vítimas desta doença que continua sendo uma ameaça global de saúde pública e, apesar disso, atualmente vem sendo relegada a um segundo plano pelas grandes indústrias farmacêuticas por ser considerada uma doença cuja quimioterapia não teria um retorno econômico atrativo, por afetar na atualidade principalmente a população pobre de países pobres. ${ }^{1}$

$\mathrm{O}$ agente causador da malária apresenta um ciclo de vida complexo dividido entre o inseto vetor e o hospedeiro humano, onde ele infecta tanto células do fígado quanto do sangue, o que dificulta bastante a ação de fármacos. Estas características de grande variabilidade em mutabilidade têm impedido o desenvolvimento de vacinas eficientes contra a malária. ${ }^{3}$ Some-se a isso o fato do Plasmodium apresentar grande capacidade de sofrer mutações que levam à resistência a quimioterapia, fenômeno que já fez com que excelentes antimaláricos do passado, como a cloroquina, se tornassem completamente inúteis em algumas regiões na atualidade. Podese esperar que a resistência eventualmente venha a atingir qualquer antimalárico desenvolvido no futuro, fazendo com que a busca por novos fármacos para os alvos conhecidos, como também a busca por novos alvos para a quimioterapia, se torne um desafio contínuo para a comunidade científica. O descobrimento de novos alvos para a quimioterapia da malária certamente tem como passo mais importante a recente publicação do genoma do $P$. falciparum, ${ }^{59}$ que pode levar à descoberta de novas proteínas específicas e com funções exclusivas no parasita, sendo excelentes potenciais alvos para o desenvolvimento de quimioterapia seletiva e eficiente.

Esperamos que o presente trabalho contribua para estimular aqueles que iniciam a carreira científica e queiram abraçar o desafio de dedicar seu trabalho em prol do desenvolvimento de conhecimentos que potencializem o descobrimento de tratamentos apropriados para as inúmeras doenças atualmente negligenciadas, como a malária. 


\section{AGRADECIMENTOS}

Ao CNPq, à CAPES, à FAPERJ e ao Instituto do Millenium pelo apoio financeiro.

\section{REFERÊNCIAS}

1. Foye, W. O.; Lemke, T. L.; Williams, D. A.; Principles of Medicinal Chemistry, $4^{\text {th }}$ ed., Williams \& Wilkins: Philadelphia, 1995.

2. The World Health Organization report, WHO Publications, Geneva, 1997.

3. Soares, I. S.; Rodrigues, M. M.; Braz. J. Med. Biol. Res. 1998, 31, 317.

4. Santos Filho, O. A.; Tese de Doutorado, Instituto Militar de Engenharia, Brasil, 2000

5. Peters, W.; Adv. Parasitol. 1998, 41, 1

6. Foote, S. J.; Cowman, A. F.; Acta Tropica 1994, 56, 157.

7. Newton, P.; White, N.; Annu. Rev. Med. 1999, 50, 179.

8. White, N. J.; Olliaro, P. L.; Parasitol. Today 1996, 12, 399.

9. Bruce-Chwatt, L. J. Em Malaria: Principles and Practice of Malariology; Wernsdorfer, W. H.; McGregor, I,eds.; Churchill Livingstone: Edinburgh, 1988, p. 1-59.

10. Celli, A.; Storia della malaria nell'agro romano, Academia dei Lincei: Roma, 1925

11. Duffy, J.; Epidemics in Colonial América, Lousiana State University Press: Baton Rouge, 1953.

12. Russel, P. F.; Bulletin of the New York Academy of Medicine 1968, 44, 623.

13. Ackerknecht, E. H.; Malaria in the Upper Mississipi Valley, 1760-1900, Johns Hopkins Press: Baltimore, 1966.

14. Marques, A. C.; Pinheiro, E. A.; Motta, E. G. F.; Resumos do XIX Congresso Brasileiro de Higiene, Rio de Janeiro, Brasil, 1977.

15. Marques, A. C.; Revista Brasileira de Malariologia e Doenças Tropicais 1979, 31, 137.

16. Rey, L., org.; Parasitologia, Guanabara-Koogan Ed.: Rio de Janeiro, 2001.

17. Sawyer, D.; Sawyer, D. R. T. O.; Malaria on the Amazon Frontier: Economic and Social Aspects of Transmision and Control, Cedeplar: Belo Horizonte, 1987

18. Tauil, P. L.; Estudo de Alguns Aspectos da Epidemia de Malária em Porto Nacional (Go) Goiânia, UFGO: Goiânia, 1981.

19. Tauil, P. L.; Resumos do XVII Congresso da Sociedade Brasileira de Medicina Tropical, Ribeirão Preto, Brasil, 1982.

20. Marques A. C.; Pinheiro, E. A.; Revista Brasileira de Malariologia e Doenças Tropicais 1982, 34, 1 .

21. http://www.saude.gov.br - Coordenação Geral do Programa Nacional de Controle da Malária/Secretaria de Vigilância em Saúde/Ministério da Saúde, acessada em Abril 2007.

22. http://www.malariasite.com/malaria/history_wars.htm, acessada em Julho 2006.

23. Ognibene, A. J.; Barret O.; Internal Medicine in Vietnam, Washington, D. C., Office of the Surgeon General and Center for Military History, U. S. Army eds., 1982, vol. 2.

24. Robinette, D.; A report of the Committee for the Study on Malarial Prevention and Control: Status Review and Alternative Strategies, Division of International Health, Institute of Medicine, National Academy Press: Washington D.C., 1991.

25. http://www.exercito.gov.br/03Brafor/Amazonia/doetropi/0011806.htm, acessada em Julho 2006

26. http://www.exercito.gov.br/04Maoami/missaopaz/monua/noticias/2006/ 07jul06/malaria.htm, acessada em Julho 2006.

27. http://www.exercito.gov.br/04Maoami/missaopaz/minustah/noticias/2006/ 07jul06/malaria.htm, acessada em Julho 2006

28. Stanley, C.; Oaks, J. R.; Violaine, S.; Mitchell, G. W.; Charles, C. J., eds.; Malaria-Obstacles and opportunities A report of the Committee for the
Study on Malarial Prevention and Control: Status Review and Alternative Strategies, Division of International Health, Institute of Medicine, National Academy Press: Washington D.C., 1991

29. Veronesi, R.; Doenças Infecciosas e Parasitárias, $7^{\text {a }}$ ed., Ed. Guanabara: Rio de Janeiro, 1982.

30. http://www.cdc.gov/malaria/biology/life_cycle.htm acessada em Agosto 2004.

31. http://www-micro.msb.lê.ac.uk/224/Bradley/Biology.html, acessada em Agosto 2004.

32. http://www-micro.msb.lê.ac.uk/224/Bradley/References.html, acessada em Agosto 2004.

33. Robert, A.; Benoit-Vical, F.; Dechy-Cabaret, O.; Meunier, B.; Pure Appl. Chem. 2001, 73, 1173

34. Silva, T. H. A.; Oliveira, M. T.; Santos, H. F.; Oliveira, A. B.; Almeida, W. B.; Quim. Nova 2005, 28, 244.

35. Delfino, R. T.; Santos-Filho, O. A.; Figueroa Villar, J. D.; J. Braz. Chem. Soc. $2002,13,727$.

36. Russell, P. F.; Man's Mastery of Malaria, Oxford University Press: London, 1955.

37. Gregson, A.; Plowe, C. V.; Pharmacological Rev. 2005, 57, 117.

38. Gangjee, A.; Jain, H. D.; Phan, J.; J. Med. Chem. 2006, 49, 1055

39. Yuvaniyama, J.; Chitnumsub, P.; Kamchonwongpaisan, S.; Vanichtanankul, J.; Sirawaraporn, W.; Taylor, P.; Walkinshaw, M. D.; Yuthavong, Y.; Nat. Struct. Biol. 2003, 10, 357.

40. França, T. C. C.; Medeiros, A. L.; Santos Filho, O. A.; Santos, E. C. P.; Figueroa-Villar, J. D.; J. Braz. Chem. Soc. 2004, 15, 450.

41. Sirawaraporn, W.; Sathitkul, T.; Sirawaraporn, R.; Yuthavong, Y.; Santi, D.V.; Proc. Natl. Acad. Sci. U.S.A. 1997, 94, 1124.

42. Hekmat-Nejad, M.; Rathod, P.K.; Chemotherapy 1996, 40, 1628.

43. Delfino, R. T.; Santos Filho, O. A.; Figueroa-Villar, J. D.; Biophys. Chem. 2002, 98, 287.

44. Santos Filho, O. A.; Alencastro, R. B.; Figueroa-Villar, J. D.; Biophys. Chem. 2001, 91, 305.

45. França, T. C. C.; Pascutti, P. G.; Ramalho, T. C.; Figueroa-Villar, J. D.; Biophys. Chem. 2005, 115, 1.

46. França, T. C. C.; Wilter, A.; Pascutti, P. G.; Ramalho, T. C.; Figueroa-Villar, J. D.; J. Braz. Chem. Soc. 2006, 17, 1383.

47. Wright, C. W.; J. Ethnopharmacol. 2005, 100, 67.

48. Hyde, J. E.; Microbes and Infection 2002, 4, 165.

49. Hastings, I. A.; Donnelly, M. J.; Drug Resistance Updates 2005, 8, 43.

50. Hasting, I. M.; D’Alessandro, U.; Parasitol. Today 2000, 16, 340

51. Targett, G.; Drakeley, C.; Jawara, M.; J. Infect. Dis. 2001, 183, 1254.

52. Nosten, F.; Brasseur, P.; Drugs 2002, 62, 1315.

53. Hildebrando, L.; Oliveira, V. E. G.; Ciência \& Saúde Coletiva 2002, 7, 49.

54. Guerin, P. J.; Olliaro, P.; Nosten, F.; Druilhe, P.; Laxminarayan, R.; Binka, F.; Kilama, W. L.; Ford, N.; White, N. J.; Infect. Diseases 2002, 2, 564

55. Hyde, J. E.; Pharmacol. Ther. 1990, 48, 45.

56. Sibley, C. H.; Hyde, J. E.; Sims, P. F. G.; Plowe, C. V.; Kublin, J. G.; Mberu, E. K.; Cowman, A. F.; Winstanley, P. A.; Watkins, W. M.; Nzila, A. M.; Trends Parasitol. 2001, 17, 582

57. Winstanley, P. A.; Parasitol. Today 2000, 16, 146.

58. Cowman, A. F.; Crabb, B.S.; Cell 2006, 124, 755.

59. Gardner, M. J.; Hall, N.; Fung, E.; White, O.; Berriman, M.; Hyman, R. W.; Carlton, J. M.; Pain, A.; Nelson, K. E.; Bowman, S.; Paulsen, I. T.; James, K.; Eisen, J. A.; Rutherford, K.; Salzberg, S. L.; Craig, A.; Kyes, S.; Chan, M. S.; Nene, V.; Shalom, S. J.; Suh, B.; Peterson, J.; Angiuoli, S.; Pertea, M.; Allen, J.; Selengut, J.; Haft, D.; Mather, M. W.; Vaidya, A. B.; Martin, D. M. A.; Fairlamb, A. H.; Fraunholz, M. J.; Roos, D. S.; Halph, S. A.; McFadden, G. I.; Cummings, L. M.; Subramanian, G. M.; Mungall, C.; Venter, J. C.; Carucci, D. J.; Hoffman, S. L.; Newbold, C.; Davies, R. W.; Fraser, C. M.; Barrell, B.; Nature 2002, 419, 498. 